\title{
"Contaminant transport to public water supply wells via flood water retention areas" published in Nat. Hazards Earth Syst. Sci., 9, 1047-1058, 2009
}

\author{
D. Kühlers ${ }^{1}$, E. Bethge ${ }^{2}$, G. Hillebrand ${ }^{3}$, H. Hollert ${ }^{4}$, M. Fleig ${ }^{5}$, B. Lehmann ${ }^{3}$, D. Maier ${ }^{6}$, M. Maier ${ }^{1}$, U. Mohrlok ${ }^{2}$, \\ and J. Wölz ${ }^{4}$ \\ ${ }^{1}$ Stadtwerke Karlsruhe GmbH (SWK), Karlsruhe, Germany \\ ${ }^{2}$ Institute for Hydromechanics (IfH), Karlsruhe, Germany \\ ${ }^{3}$ Institute for Water and River Basin Management (IWG), Karlsruhe, Germany \\ ${ }^{4}$ Institute for Environmental Research (IfU), Aachen, Germany \\ ${ }^{5}$ DVGW-Technologiezentrum Wasser (TZW), Karlsruhe, Germany \\ ${ }^{6}$ Heinrich-Sontheimer-Laboratorium (HSL), Karlsruhe, Germany
}

Erroneously, Fig. 7 of the published article duplicates Fig. 8, while its caption correctly refers to modelling results before flooding of the retention area. The missing Fig. 7 is given below and should be replaced in the publication.

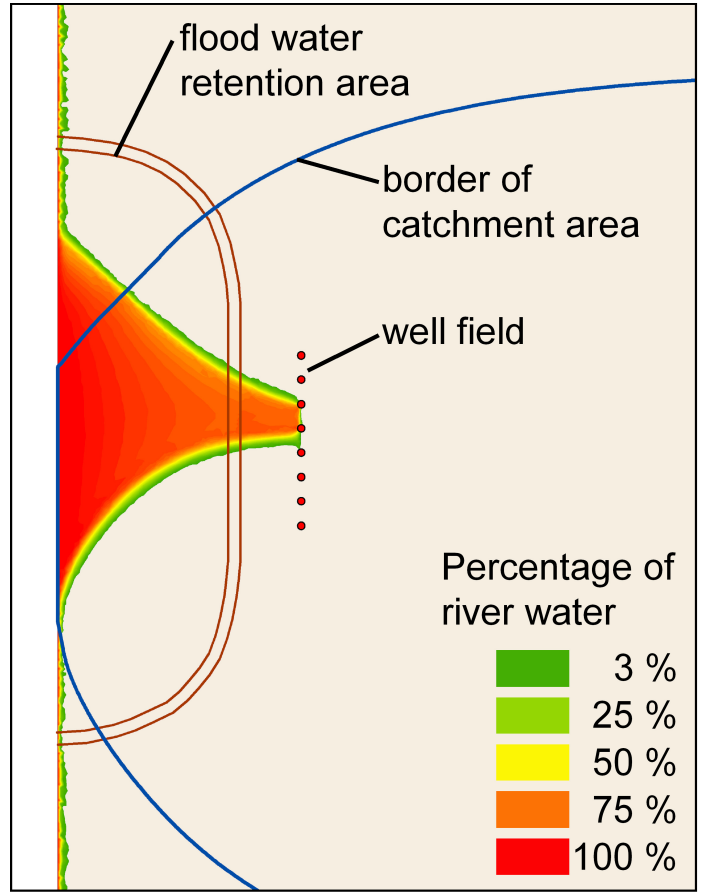

Fig. 7. River water in the aquifer before flooding of the retention area.
Correspondence to: D. Kühlers (dirk.kuehlers@stadtwerke-

karlsruhe.de) 